\title{
Methotrexate therapy of T-cell large granular lymphocytic leukemia impact of STAT3 mutation
}

\author{
Zhi-Yuan Qiu ${ }^{1,2}$, Lei Fan ${ }^{1}$, Rong Wang ${ }^{1}$, Robert Peter Gale ${ }^{3}$, Hua-Jin Liang ${ }^{1}$, Man \\ Wang $^{1}$, Li Wang ${ }^{1}$, Yu-Jie Wu${ }^{1}$, Chun Qiao ${ }^{1}$, Yao-Yu Chen ${ }^{1}$, Wei $\mathbf{X u}^{1}$, Jun Qian ${ }^{4}$, \\ Jian-Yong Li ${ }^{1}$ \\ ${ }^{1}$ Department of Hematology, the First Affiliated Hospital of Nanjing Medical University, Jiangsu Province Hospital, Collaborative \\ Innovation Center for Cancer Personalized Medicine, Nanjing, China \\ ${ }^{2}$ Department of Oncology, the Affiliated People's Hospital of Jiangsu University, Zhenjiang, Jiangsu, China \\ ${ }^{3}$ Haematology Research Centre, Division of Experimental Medicine, Department of Medicine, Imperial College London, \\ London, United Kingdom \\ ${ }^{4}$ Department of Hematology, the Affiliated People's Hospital of Jiangsu University, Zhenjiang, Jiangsu, China \\ Correspondence to: Wei Xu, email: xuwei10000@hotmail.com \\ Jian-Yong Li, email: lijianyonglm@medmail.com.cn \\ Jun Qian, email: qianjun0007@hotmail.com.cn
}

Keywords: T-cell large granular lymphocytic leukemia, methotrexate, STAT3

Received: February 05, $2016 \quad$ Accepted: August 09, $2016 \quad$ Published: August 17, 2016

ABSTRACT

T-cell large granular lymphocytic leukemia (T-LGLL) is a rare haematologic neoplasm. Consequntly, there are no large prospective studies of therapy and no uniform therapy recommendations. We analyzed data from 36 subjects receiving methotrexate alone $(N=27)$ or with prednisone $(N=9)$ as initial therapy. 31 subjects responded $(86 \%, 95 \%$ confidence interval $[C I], 73,95 \%)$ with 8 complete responses and 23 partial responses. Median time-to-response was 3 months (range, 1-5 months). Median response duration was 20 months (range, 2-55 months). $\beta_{2}$-microoglobulin $\left(\beta_{2}-M G\right)$ and erythrocyte sedimentation rate (ESR) decreased significantly posttherapy $(P<0.0001)$. Pure red cell aplasia (PRCA) was present in 18 subjects $(50 \%)$ of our subjects and responded well to methotrexate. 26 subjects $(72 \%)$ were tested for STAT3 mutation. 9 with a mutation had a median treatment-free survival of 5 months (range, 0.5-13 months), significantly briefer than that of 17 subjects without a STAT3 mutation (19 months, range, 3-97 months; $P=0.012$; log-rank test). Methotrexate with or without prednisone is an effective initial therapy of persons with T-LGLL with wild-type STAT3.

\section{INTRODUCTION}

T-cell large granular lymphocytic leukemia (T-LGLL) is a lympho-proliferative neoplasm of cytotoxic $\mathrm{T}$ cells [1]. There is no standard therapy but immune suppression is commonly used when therapy is needed. The three most commonly used drugs are methotrexate, cyclosporine and cyclophosphamide. Treatment outcomes are heterogeneous and there is only one comparative study which shows immune suppression is effective and mutational profiling predicts response [2].

T-LGLL can present as failure of hematopoiesis or immune-mediated destruction of one or several cell lines including RBCs, neutrophils, and platelets. T-LGLL associated pure red cell aplasia (PRCA) accounts for a significant portion of secondary PRCA [3]. Because T-LGLL and T-LGLL associated PRCA are rare optimal long-term outcomes after immune suppressive therapy are controversial. We report results using methotrexate as initial therapy of T-LGLL in 36 subjects most of whom also had PRCA. Correlative studies were conducted to determine if biomarkers or genetic analysis could predict therapy response.

\section{RESULTS}

Clinical variables

Data on the 36 subjects are displayed in Table 1. There were 20 males. Median age at diagnosis was 60 years 
(range, 38-89 years). Median follow-up is 39 months (range, 8-94 months).

\section{Laboratory results}

Four subjects had anaemia (Hemoglobin $<110 \mathrm{~g} / \mathrm{L})$ and decreases in neutrophils $(<1.5 \times 10 \mathrm{E}+9 / \mathrm{L})$ and platelets $(<100 \times 10 \mathrm{E}+9 / \mathrm{L}) .24$ had only neutropenia, severe in 1 . Thrombocytopenia was present in 7 subjects. Anaemia was present in 34 (Table 1). 18 subjects had PRCA (Table 1). 23 subjects tested had normal cytogenetics. Three subjects had a positive rheumatoid factor test one of whom had rheumatoid arthritis. All subjects had clonal rearrangement of the T-cell receptor.

\section{Immune phenotypes and $\mathrm{V} \beta$ expression}

34 subjects had the predominant LGL phenotype $\left(\mathrm{CD} 3+\mathrm{CD} 8+\mathrm{CD} 57+\mathrm{CD} 56^{-}\right)$and 2 subjects with CD3+CD4+CD57+CD56-. 33 subjects were TCR $\alpha \beta+$ and 3 subjects were TCR $\gamma \delta+$. Flow cytometric variable $\beta$-chain repertoire (FC-V $\beta$ ) analysis was done in 30 subjects. $22(73 \%)$ subjects had a restricted $V \beta$ reactivity pattern; V $\beta 13.1$ was relatively frequent (Figure 1). There was complete lack of $\mathrm{V} \beta$ expression in 8 subjects.

\section{Response}

27 subjects received methotrexate only and 9, methotrexate and prednisone. 31 subjects $(86 \%$ $[73,95 \%])$ responded with 8 complete responses and 23 partial responses. We compared initial characteristics of non-responders, partial responders and complete responders, but no differences were found in terms of age, gender, splenomegaly, hepatomegaly, symptoms at diagnosis, LDH, LGL count, neutropenia, anemia and thrombocytopenia. Median teatment-free-survival was 13.1 months (range, 0.5-97 months). Median timeto-response (TTR) was 3 months (range, 1-5 months). Median response duration was 20 months (range, 2-55 months). 9 subjects receiving methotrexate and prednisone had a median time-to-response (TTR) of 2.3 months (range, 1-4 months), briefer than the TTR in the 26 subjects receiving methotrexate alone, 2.7 months (range, $1-5$ months; $P=0.27$ ). 3 subjects who maintained their response were lost to follow-up. 30 subjects maintained their response. One subject died from disease progression. By the end of follow-up, 22 subjects were receiving methotrexate (16 subjects received continuous methotrexate and 6 received lower doses methotrexate). 4 subjects maintained their response after discontinuing methotrexate. 4 subjects relapsed and received cyclosporine of whom 3 responded (partial responses). The non-responder to cyclosporine then received low-dose oral cyclophosphamide achieving a complete response.
In the 18 subjects with PRCA there were 6 complete and 11 partial responses with an overall response rate of $94 \%$ (95\% confidence interval, 73-100\%). Median timeto-response was 3 months (range, 1-5 months). Median response duration was 20 months (range, 5-55 months). Response rate in subjects with PRCA was not significantly different than in all subjects.

\section{Serum biomarkers}

We also assessed dynamic changes of ESR and $\beta_{2}$-MG in serum of subjects as a marker of therapy response. Baseline levels (mean $\pm \mathrm{SEM}$ ) of serum $\beta_{2}-\mathrm{MG}$ and ESR levels were $4.67 \pm 2.76 \mathrm{mg} / \mathrm{L}$ and $61.2 \pm$ $41.1 \mathrm{~mm} / \mathrm{h}$. Post-therapy values at the time of best response were $2.76 \pm 1.53 \mathrm{mg} / \mathrm{L}(P=0.003)$ and $20.1 \pm$ $21.0 \mathrm{~mm} / \mathrm{h}(P<0.001)$.

\section{Toxicity}

Adverse events were uncommon and none required stopping therapy. There were 2 grade- 1 toxicities, one an alanine aminotransferase increase and one a total bilirubin increase each in 1 subject. Grade- 2 toxicities included oral mucositis (1 subject) and nausea (3 subjects).

\section{STAT3 mutation}

26 subjects were tested for STAT3 mutation. 9 had mutations including STAT3 $^{\mathrm{Y} 640 \mathrm{~F}}(N=4)$, STAT3 $^{\mathrm{D} 661 \mathrm{Y}}$ $(N=2), \operatorname{STAT3}^{\mathrm{V} 671 \mathrm{~F}}(N=1), \operatorname{STAT3S}^{614 \mathrm{R}}(N=1)$ and $\operatorname{STAT3}^{\mathrm{E} 616 \mathrm{~V}}(N=1)$. Subjects with STAT3 mutation had briefer treatment-free survival than subjects with wildtype STAT3 (5 mo [range, 0.5-13 mo] vs. 19 mo [range, 3-97 mo]; $P=0.012$; Figure 2). Time-to-response and response-duration were also briefer in subjects with a STAT3 mutation but these differences were not significant. There were too few subjects to test this association in multivariate analyses. Comparison of the clinical variable in subjects with or without STAT3 mutation is shown in Table 2.

\section{DISCUSSION}

We report a high response rate with methotrexate with or without prednisone as initial therapy of T-LGLL. Subjects with associated PRCA had correspondingly high response rates and long response durations. Others report similar response rate but many more relapses [4-6]. Time-to-response of subjects receiving methotrexate and prednisone was briefer subjects receiving methotrexate only but this allocation was not randomized and requires confirmation. No responder relapsed immediately after discontinuing prednisone. Response rates were similar in persons with and without PRCA. 
Table 1: Subject-related variables

\begin{tabular}{|l|c|}
\hline $\mathrm{N}$ & 36 \\
\hline Male & 20 \\
\hline Age (median;range) & $60(38-89)$ \\
\hline Symptoms at diagnosis & 35 \\
\hline PRCA & 18 \\
\hline Neutrophils $<1.5 \times 10 \mathrm{E}+9 / \mathrm{L}$ & 24 \\
\hline Neutrophils $<0.5 \times 10 \mathrm{E}+9 / \mathrm{L}$ & 1 \\
\hline Hemoglobin $<110 \mathrm{~g} / \mathrm{L}$ & 34 \\
\hline Platelet $<100 \times 10 \mathrm{E}+9 / \mathrm{L}$ & 7 \\
\hline LGL $\times 10 \mathrm{E}+9 / \mathrm{L}$ & $2.9 \pm 1.9$ \\
Mean \pm SD & 3 \\
\hline Hepatomegaly & 18 \\
\hline Splenomegaly & 2 \\
\hline Lymphadenopathy & 18 \\
\hline LDH $>250 \mathrm{U} / \mathrm{L}$ & 3 \\
\hline RF & 7 \\
\hline ANA & 24 \\
\hline ESR $>20 \mathrm{~mm} / \mathrm{h}$ & 23 \\
\hline$\beta 2-\mathrm{MG}>3.0 \mathrm{mg} / \mathrm{L}$ & \\
\hline
\end{tabular}

RF, rheumatoid factor; PRCA, pure red cell aplasia; LGL, large granular lymphocyte; ANA, anti-nuclear antibody; $\beta 2-\mathrm{MG}$, $\beta 2$-microglobulin; ESR, erythrocyte sedimentation rate.

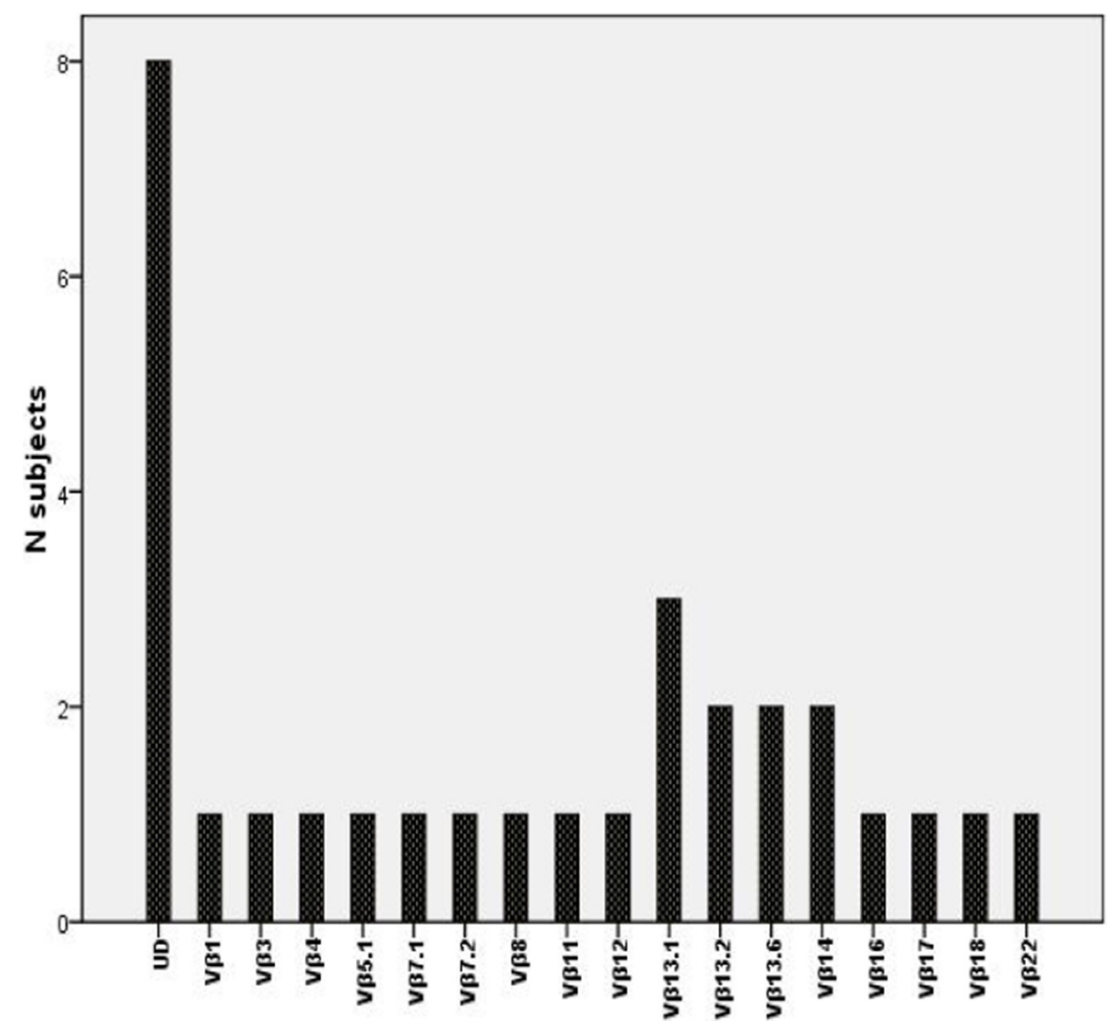

Figure 1: TCR-vß (UD: un-dectable). 
Table 2: Clinical differences between patients with or without STAT3 mutation

\begin{tabular}{lccc}
\hline \multicolumn{1}{c}{ Variable } & $\begin{array}{c}\text { Patients with STAT3 mutation } \\
(\%)\end{array}$ & $\begin{array}{c}\text { Patients without } \\
\text { STAT3 mutation (\%) }\end{array}$ & $\boldsymbol{P}$ \\
\hline Gender & $4(44.4)$ & $9(47.1)$ & 1.0 \\
$\quad$ Male & $5(55.6)$ & $8(52.9)$ & 0.53 \\
Female & & & \\
Age (years) & $58.1 \pm 9.5$ & $55.7 \pm 10.4$ & 0.41 \\
$\quad$ Mean \pm SD & $6(66.7)$ & $7(41.2)$ & 0.12 \\
LDH >250U/L & $9(100.0)$ & $10(66.7)$ & 1.0 \\
B2-MG >3.0 mg/L (n=24) & $9(94.1)$ & $16(54.5)$ & 1.0 \\
Symptoms at diagnosis, no. (\%) & $7(77.8)$ & $12(70.6)$ & 0.35 \\
Neutropenia, no. (\%) & $8(88.9)$ & $17(100)$ & 1.0 \\
Anemia, no. (\%) & $1(11.1)$ & $1(5.9)$ & 0.095 \\
Thrombocytopenia, no. (\%) & & $2.83 \pm 1.72$ & 0.11 \\
LGL count in PB, $\times 10 \mathrm{E}+9 / \mathrm{L}$ & $3.89 \pm 2.44$ & $0(0)$ & 0.11 \\
Mean \pm SD & $2(22.2)$ & $7(41.2)$ & 0.21 \\
Hepatomegaly, no. (\%) & $7(77.8)$ & $8(47.1)$ & \\
Splenomegaly, no. (\%) & $7(77.8)$ & & \\
PRCA, no. (\%) & & & \\
\hline
\end{tabular}

PB: peripheral blood; STAT3: signal transducer and activator of transcription 3.

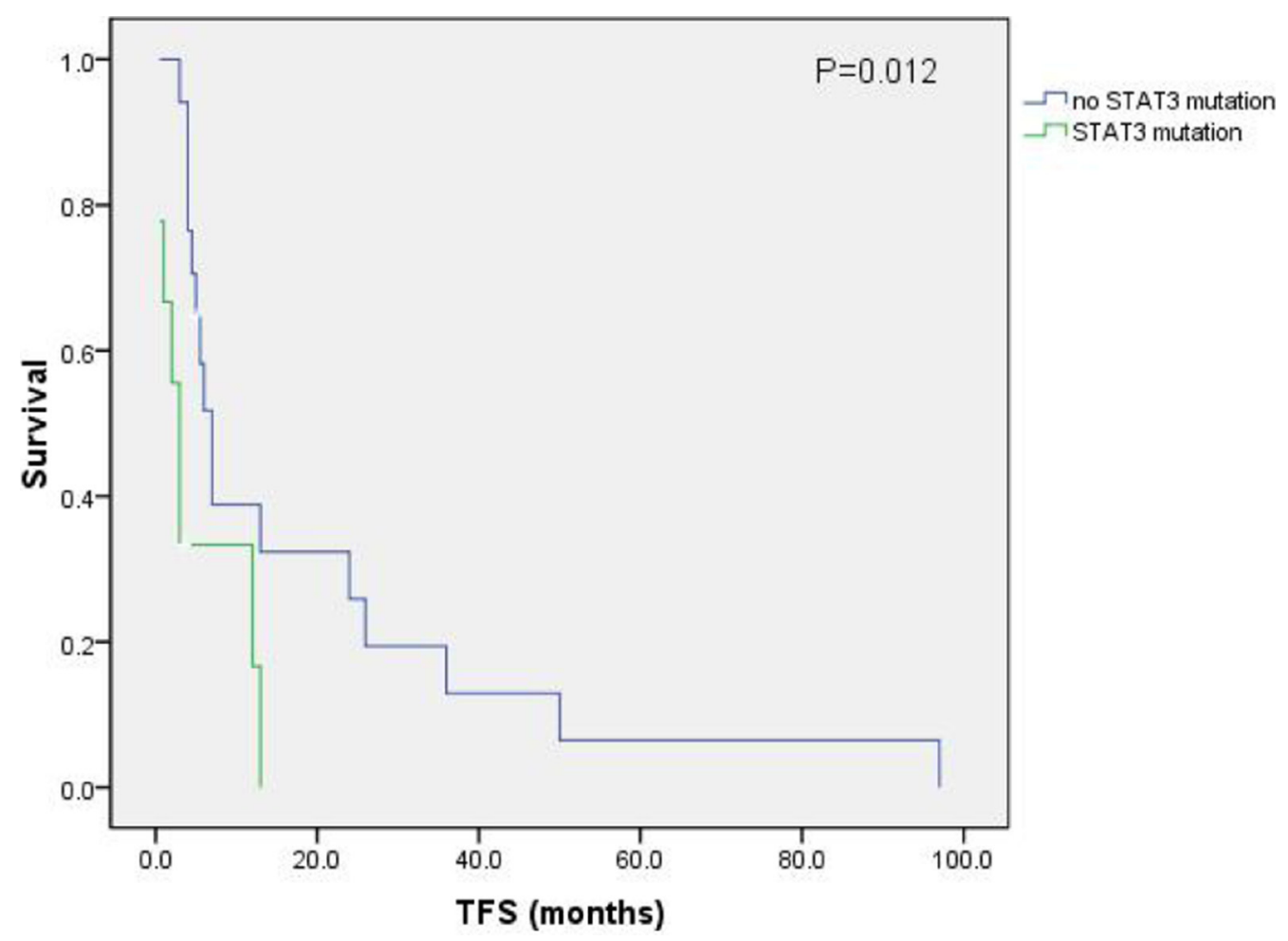

Figure 2: Treatment-free-survival. 
$30-40 \%$ of persons with T-LGLL have mutations in STAT3 [7, 8]. We found STAT3 mutations in 9 of 26 subjects $(35 \%)$. Like some, but in contrast to other reports, we found an association between STAT3 mutation and PRCA $[8,9]$. We also found differences in time-toresponse and treatment-free survival in subjects with and without STAT3 mutations. Others reported STAT3 ${ }^{\mathrm{Y} 640 \mathrm{~F}}$ is associated with response to methotrexate [2]. These data suggest screening for STAT3 mutations may be useful.

There are important limitations to our study. Numbers of subjects is small compromising our power to detect differences. Although the series was consecutive we cannot exclude referral biases. Assignment to prednisone was not random. Finally, there were too few subjects to test the association between STAT3 mutation and treatment-free survival. Because of these limitations our conclusions require validation. In summary, methotrexate alone or combined with prednisone is an effective initial therapy of T-LGLL with high response rates and durable responses. Persons with associated STAT3 mutation had worse outcome than those with wild-type STAT3.

\section{MATERIALS AND METHODS}

\section{Subjects}

36 consecutive subjects with newly-diagnosed, untreated T-LGLL were seen February, 2005 to October, 2014 in the First Affiliated Hospital of Nanjing Medical University (Jiangsu Province Hospital). Subjects gave written informed consent and the University and Institutional Review Boards approved the study which conformed to the Declaration of Helsinki. Diagnosis of T-LGLL was based on WHO criteria including: (1) blood morphology; (2) presence of an abnormal cytotoxic lymphocyte population with expression of CD3, CD8 and CD57; (3) LGL concentration > $2 \times 10 \mathrm{E}+9 / \mathrm{L}$; (4) T-cell clonality; and (5) persistence $>6$ months. PRCA was defined as reported [10].

\section{Laboratory data}

Data collected at diagnosis included age, sex, symptoms, hepatomegaly, splenomegaly, lymphadenopathy, WBC, hemoglobin concentration, neutrophil, platelet, lymphocyte and LGL levels, lactate dehydrogenase (LDH), erythrocyte sedimentation rate (ESR) and serum $\beta_{2}$ microglobulin $\left(\beta_{2}-\mathrm{MG}\right)$.

\section{Flow cytometric analysis for immune phenotype and T-cell receptor $\mathrm{V} \beta$ repertoire (TCR-VB)}

Immune phenotypic analysis of $\mathrm{PB}$ and/or bone marrow (BM) samples were determined using specific antibodies against CD2 (Leu-5b), CD3 (SK7), CD4 (Leu-3a), CD5 (Leu-1), CD7 (3A1), CD8 (Leu-2a), CD16 (3G8), CD56 (NCAM16.2), CD57 (HNK-1), TCR $\alpha \beta$ (WT31) and $\mathrm{TCR} \gamma \delta(11 \mathrm{~F} 2)$. All antibody conjugates were from BD Biosciences (San Jose, CA, USA). A 4-color flow cytometric immune phenotype strategy, antibodies to CD3, CD8 and the IO Test Beta Mark TCRV $\beta$ Repertoire kit (Beckman Coulter, Marseille, France) were used. Analyses were done as described [11].

\section{Separation of mononuclear cells and DNA isolation}

Blood or bone marrow samples were collected at diagnosis and mononuclear cells isolated by density gradient centrifugation using Ficoll-Hypaque. Genomic DNA was extracted and purified as described using the QIAamp blood kit (Qiagen, Hilden, Germany). DNA concentration and purity were measured with Eppendorf Biophotometer (Eppendorf, Hamburg, Germany).

\section{Multiplex polymerase chain reaction (PCR) analysis for $\mathrm{T}$-cell receptor gene rearrangement}

PCR analysis for T-cell receptor gene rearrangement was performed using genomic DNA extracted from the mononuclear cells and performed as previously described [12].

\section{Analysis of STAT3 mutations}

DNA from samples from 26 consenting subjects was tested for mutations in exons 20 and 21. STAT3 amplicon sequencing and data analyses were done as described [11].

\section{Treatment}

Indications for treatment included: (1) absolute neutrophil level (ANC) $<0.5 \times 10 \mathrm{E}+9 / \mathrm{L}$; (2) recurrent infections independent of ANC; (3) symptomatic or RBCtransfusion-dependent anemia; and/or (4) autoimmune conditions such as PRCA or rheumatoid arthritis [13]. Methotrexate was given orally at a dose of $10 \mathrm{mg} / \mathrm{mE}+$ 2 weekly. Oral low-dose folic acid $(5 \mathrm{mg} / \mathrm{d})$ was given to prevent mouth ulcers. Prednisone $(0.5-1 \mathrm{mg} / \mathrm{kg} / \mathrm{d})$ could be given for $\leq 2$ months of starting methotrexate.

\section{Response criteria}

Complete response was defined as normalization of blood cell levels and reduction of LGLs to the normal range $(\mathrm{ANC}>1.5 \times 10 \mathrm{E}+9 / \mathrm{L}$; lymphocytes $<4.0 \times 10 \mathrm{E}$ $+9 / \mathrm{L}$; hemoglobin concentration $>110 \mathrm{~g} / \mathrm{L}$; platelets $>100 \times 10 \mathrm{E}+9 / \mathrm{L})$. Partial response was defined when either of the following: ANC increase $>50 \%$ and $>0.5$ but $<1.5 \times 10 \mathrm{E}+9 / \mathrm{L}$; haemoglobin concentration increase $>20 \mathrm{~g} / \mathrm{L}$ and $\mathrm{RBC}$-transfusion-independence but $<110 \mathrm{~g} / \mathrm{L}$. No response was defined as a response $<$ partial response $>4$ months after starting methotrexate but without disease progression. Progressive disease was defined as worsening 
of hematologic parameters in subjects previously achieving $\geq$ partial response. Toxicity was graded using the modified NCI Common Terminology Criteria (CTC, version 4.0). Blood cell levels and differentials and kidney and liver function tests were analyzed monthly. Treatment was continued in responders until relapse, death or withdrawal of consent.

\section{Endpoints}

Time-to-response was defined as the interval from starting methotrexate to $a \geq 50 \%$ improvement in blood cell level(s). Response duration was defined as the interval from declaring response to relapse. Treatment-freesurvival was defined as the interval from date of diagnosis to starting methotrexate. Survival was defined as the interval from diagnosis to death or last follow-up.

\section{Statistical analyses}

Statistical analyses used the SPSS program for Windows (version 16.0). Comparisons of proportions and ranks of variables between groups were performed by chisquared-test, Fisher exact test or Student $t$-test. KaplanMeier survival estimates were constructed and differences compared by log-rank test. An effect was considered statistically significant at $P<0.05$. $P$-values were two sided.

\section{ACKNOWLEDGMENTS AND FUNDING}

Supported by National Natural Science Foundation of China (No. 81200360, 81100352, 81170485, 81170486, 81170488, 81370657), Natural Science Foundation of Jiangsu Province (No.BK2012484, BK20161354), Key Projects of Health Department of Jiangsu Province (No. K201108), Jiangsu Province's Medical Elite Program (No. RC2011169), Project Funded by the Priority Academic Program Development of Jiangsu Higher Education Institute (No. JX10231801), Project of National Key Clinical Specialty. National Science \& Technology Pillar Program (No. 2014BAI09B12), and Project funded by Jiangsu Provincial Special Program of Medical Science (No. BL2014086).

\section{CONFLICTS OF INTEREST}

None.

\section{REFERENCES}

1. Loughran TP Jr, Kadin ME, Starkebaum G, Abkowitz JL, Clark EA, Disteche C, Lum LG, Slichter SJ. Leukemia of large granular lymphocytes: association with clonal chromosomal abnormalities and autoimmune neutropenia, thrombocytopenia, and hemolytic anemia. Ann Intern Med 1985; 102:169-175.

2. Loughran Jr TP, Zickl L, Olson TL, Wang V, Zhang D, Rajala HL, Hasanali Z, Bennett JM, Lazarus HM, Litzow MR, Evens AM, Mustjoki S, Tallman MS, et al. Immunosuppressive therapy of LGL leukemia: prospective multicenter phase II study by the eastern cooperative oncology group (E5998). Leukemia. 2015; 29:886-894.

3. Go RS, Lust JA, Phyliky RL. Aplastic anemia and pure red cell aplasia associated with large granular lymphocyte leukemia. Semin Hematol. 2003; 40:196-200.

4. Loughran Jr TP, Kidd PG, Starkebaum G. Treatment of large granular lymphocyte leukemia with oral low-dose methotrexate. Blood. 1994; 84: 2164-2170.

5. Loughran Jr TP, Yao X, Bennett JM, Litzow MR, Evens AM, Tallman MS. Results of a prospective multicenter phase ii study of initial treatment with methotrexate in LGL leukemia (ECOG Protocol E5998). ASH Annual Meeting Abstracts. 2010; 116:702.

6. Bareau B, Rey J, Hamidou M, Donadieu J, Morcet J, Reman O, Schleinitz N, Tournilhac O, Roussel M, Fest T, Lamy T. Analysis of a French cohort of patients with large granular lymphocyte leukemia: a report on 229 cases. Haematologica. 2010; 95:1534-1541.

7. Koskela HL, Eldfors S, Ellonen P, van Adrichem AJ, Kuusanmäki H, Andersson EI, Lagström S, Clemente MJ, Olson T, Jalkanen SE, Majumder MM, Almusa $\mathrm{H}$, Edgren $\mathrm{H}$, et al. Somatic STAT3 mutations in large granular lymphocytic leukemia. N Engl J Med. 2012; 366:1905-1913.

8. Jerez A. Clemente MJ, Makishima H, Koskela H, Leblanc F, Peng Ng K, Olson T, Przychodzen B, Afable M, GomezSegui I, Guinta K, Durkin L, Hsi ED, et al. STAT3 mutations unify the pathogenesis of chronic lymphoproliferative disorders of NK cells and T-cell large granular lymphocyte leukemia. Blood. 2012; 120:3048-3057.

9. Qiu ZY, Fan L, Wang L, Qiao C, Wu YJ, Zhou JF, Xu W, Li JY. STAT3 mutations are frequent in T-cell large granular lymphocytic leukemia with pure red cell aplasia. J Hematol Oncol. 2013; 6:82-84.

10. Kwong YL, Wong KF, Liang RH, Chu YC, Chan LC, Chan TK. Pure red cell aplasia: clinical features and treatment results in 16 cases. Ann Hematol. 1996; 72:137-140.

11. Qiu ZY, Shen WY, Fan L, Wang L, Yu H, Qiao C, Wu YJ, Lu RN, Qian J, He GS, Xu W, Li JY. Assessment of clonality in T-cell large granular lymphocytic leukemia: flow cytometric $\mathrm{T}$ cell receptor $\mathrm{V} \beta$ repertoire and $\mathrm{T}$ cell receptor gene rearrangement. Leuk. Lymphoma. 2015; 56:324-331.

12. van Dongen JJ, Langerak AW, Brüggemann M, Evans PA, Hummel M, Lavender FL, Delabesse E, Davi F, Schuuring E, García-Sanz R, van Krieken JH, Droese J, González D, et al. Design and standardization of 
PCR primers and protocols for detection of clonal immunoglobulin and T-cell receptor gene recombinations in suspect lymphoproliferations: report of the BIOMED-2 Concerted Action BMH4-CT98-3936. Leukemia. 2003; 17:2257-2317.
13. Lamy T, Loughran Jr TP. How I treat LGL leukemia. Blood. 2011; 117:2764-2774. 